\title{
VENOMOUS SNAKEBITE IN PREGNANCY AND GOOD OUTCOME -A CASE REPORT
}

\author{
MOHAMMAD ALI ${ }^{1}$, MD ROBED AMIN ${ }^{2}$, MOHAMMAD BELALUL ISLAM $^{3}$, MOHAMMAD HARESUR RAHMAN $^{3}$, \\ MD.MAHBUBUL ISLAM MOJUMDAR ${ }^{4}$
}

\begin{abstract}
:
Worldwide occurrence of snakebite in pregnancy is little known in medical literature. Furthermore to the best of our knowledge there is no case report on Krait envenomation in pregnancy in Bangladesh. It carries significant fetal wastage and maternal morbidity and mortality. Here we report a mutligravida aged 27 years at her 24 weeks of gestation with krait bite with neuroparesis with good obstetrical outcome.
\end{abstract}

Key words :Snakebite, Pregnancy, Envenomation.

\section{Introduction:}

Snakebite is a potentially a life threatening medical emergency. Snake bite in pregnancy is rare $^{1}$ and medical literatures on this issue are limited and not widely available. . Studies from Africa, India and SriLanka revealed pregnant women are accounted for. $4 \%$ to $1.8 \%$ of hospitalized snakebite victims ${ }^{2}$. Snakebite carries significant fetal wastage (43\%) and maternal mortality(10\%) 3.

Snake bites are uncommon in second and third trimesters of pregnancy as they are commonly house bound.4 Venomous snakes that are commonly encountered in Bangladesh are: Krait (Bangarus), Cobra(naja) and green pit viper(Trimeresurus). Envenomation by kraits and cobras usually presents with neurotoxicity. we report a case of snake bite of 27 years old lady in second trimester of pregnancy who showed neuroparesis following krait bite and was successfully treated and having a good obstetrical outcome.

\section{Case report:}

A 27 year old multigravida (gravida 4 para 3) at her 24 weeks of her gestation presented twenty four hours following snakebite on her left foot. Patient lives in a rural area in tin shed house. It was late evening when going for water from nearby tube well on barefoot she got bitten by snake. She became frightened started screaming. Neighbors killed snake at the spot. Following bite she noticed pain and tingling sensation in the bitten area and oozing of few drops of blood..Traditional healer (Ozha) called in and he treated the patient by giving two tight tourniquet on her leg, multiple incisions around the bitten area and applying herbal product over the wound..He kept the patient in the house about 12 hours. Following four hour after snake bite patient started noticing heaviness of both eyelids, blurring vision, weakness of both lower limbs and after seven and ten hour she had had difficulty in swallowing and nasal voice respectively. She had also altered taste sensation which she noticed while taking pepper and oil as a snake bite medicine.. She had no local swelling or blister in the bitten area

The snake was brought in dead and identified. It was diagnosed as common krait by expert taxonomist (Bangarus caeruleaus)and was 2.5 feet long. It's sex had not been identified identified (Fig 1)

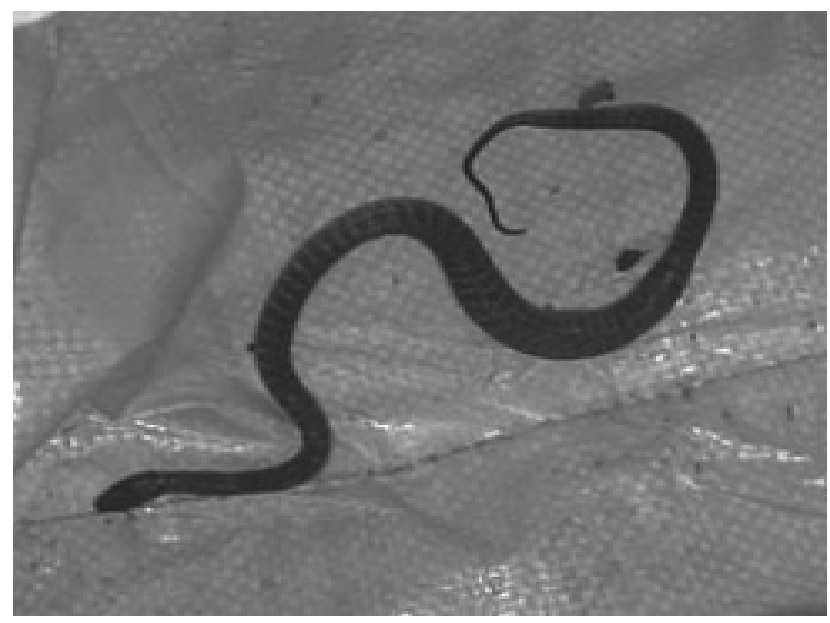

Fig1: The offending snake (Bangarus caeruleus) (copyright $M$ Ali)

1. Senior Consultant of Medicine, Comilla Medical College

2. Associate Professor of Medicine, Dhaka Medical College

3. Assistant Professor of Medicine, Comilla Medical College

5. Professor of Medicine, Comilla Medical College

Address of Correspondence: Dr Mohamamd Ali, Senior Consultant of Medicine, Comilla Medical College. E mail-mltn7@yahoo.com 
Patient was conscious and oriented on admission. Her vital signs were: blood pressure 130/70,pulse $96 /$ minute(regular), respiration $20 /$ minute, temperature $98.4 \mathrm{~F}$.There was single fang mark on her left foot and multiple incisional marks. She had bilateral ptosis with complete external ophtalmoplegia and normal gag reflex and jaw jerk(Fig 2). There was also proximal muscle weakness(grade 4 on MRC scale) in her both lower limbs with normal strength upper limb muscle. All the deep tendon jerks coordination and all modalities of sensation were found to be normal in both the upper and lower limb. Planter reflexes went down going .Per abdominal examination revealed 24 weeks uterus size. Fetal heart sounds were normal.

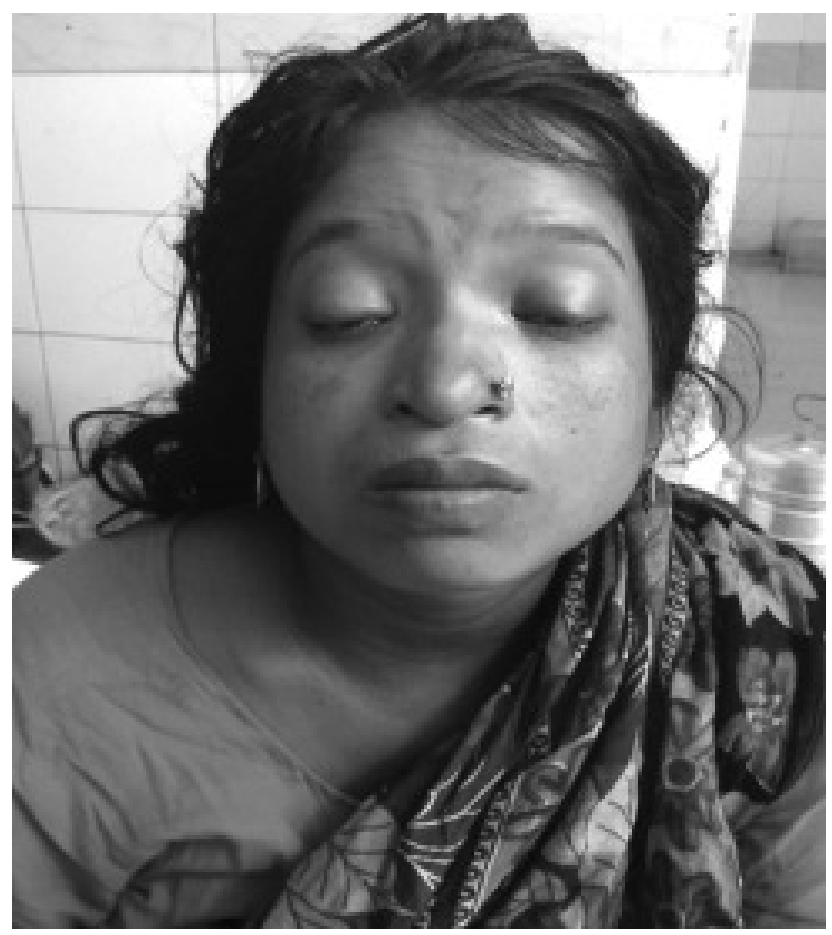

Fig.-2: Bilateral incomplete Ptosis (Copyright $M$ Ali)

On investigations: Complete hemogram revealed normal findings. Bleeding time clotting time were normal.20min WBCT was normal as were liver and renal function test. Obstetric and gynaecological consultation on pregnancy and fatal health were obtained. Obstetric ultrasonographic findings were normal.

She was administered 100ml lyophilized polyvalent anti snake venom(ASV)(10 vials ASV each of which was diluted with $10 \mathrm{ml}$ distilled water and mixed with $100 \mathrm{ml}$ of $5 \%$ dextrose in aqua saline given intravenously in four hours) along with intravenous atropine $(.6 \mathrm{mg}$ at dose of $15 \mathrm{microgram} / \mathrm{kg}$ four hourly)followed by Subcutaneous neostigmine(50 microgram/kg four hourly) until neuro toxic features got improved .Before ASV administration subcutaneous adrenaline was also given as a prophylaxis for anaphylaxis No untoward events were observed. Patient recovered completely. Although recovery was delayed, patient was discharged after eight days of hospitalization with follow up advice. On one follow up visits no untoward consequences in patient and fetal health were observed. Three months later she gave birth to a healthy baby boy through normal vaginal delivery at home with the help of female birth attendant. He is now three month old and is doing well.

\section{Discussion:}

About 82 species of snakes are found in Bangladesh. Of these only 28 species are venomous ${ }^{5}$ Among these venomous snakes krait, cobra are commonly known to be dangerous to man. There are 700000 snakes bites/year in Bangladesh with 6000 case fatalities ${ }^{6}$.Fatalites are more common in developing countries where human populations are dense, venomous snakes are plentiful, rapid access to intensive care is lacking and believes in traditional healers are prevailing.

Reports on Snake bite during pregnancy is rare in medical literature specially in Bangladesh. A review by Langely showed only 213 reported cases from 1966 to $2009^{1}$.It has significant prognostic implications on mother as well as on fetus. A literature review found over all fetal deaths ranging from $38 \%$ to $43 \%{ }^{3,7}$ with maternal deaths of $10 \%$ after snake envenomation. Another recent review has shown overall fetal loss around $10 \%$ and maternal mortality is about $4 \%$ to $5 \%^{1}$.A number of mechanism have been proposed to explain fetal death, abortion after snake bite including premature uterine contraction, direct venom toxicity abruption placenta ,fetal anoxia, supine hypotension syndrome and maternal anaphylaxis.

Kraits are common in Bangladesh as well as Nepal, India, Pakistan and Srilanka.Currentlly,12species of kraits are recognized in the world ${ }^{8}$.In Bangladesh 6 species are identified ${ }^{8}$.In most of the cases snake cannot be identified by direct inspection. Therefore, a syndromic approach by WHO guideline for management of snake bite in Southeast Asia is followed ${ }^{8}$.

Krait bites occur at night when snake comes home 
in search of its prey and someone sleeping on the floor roll on to it in their sleep. Envenomation with krait is usually presented with neurotoxic features like ptosis, opthalmoplegia, nasal voice, nasal regurgitation, neck muscle weakness and respiratory muscle paralysis. Patient may present with abdominal pain and that may mimic surgical abdomen $^{9}$.

Anti snake venom(ASV) remains the cornerstone of the management of snakebite. We used $100 \mathrm{ml}$ of polyvalent anti snake venom in our patient as she had systemic features of envenomation and no untoward events were seen. Snake venom may cross the placenta even before mother produces features of envenomation. Therefore it was recommended to give antivenom if fetal movement is slowing down even before mother has no systemic features of envenoming ${ }^{10}$.Adverse effects following administration of ASV are not uncommon. The effect of antivenom on fetus is not clear. In recent literature review showed among 96 mothers who had received ASV, 26 fetal deaths(30\%) occurred and only 2 mother $\operatorname{died}(2.1 \%)^{1}$.Senevirante et al reported $64.7 \%$ adverse fetal outcome in term of abortion and malformation in 17 patients treated with anti venom ${ }^{2}$.In one study fetal death was reported to be $30 \%$ who received antivenom versus $11.3 \%$ who did not ${ }^{1}$.This may due to more significant envenmation. Mother as well as fetus may have been more likely to die if antivenom was withheld. In pregnancy safety of anti venom is less clear. But risk of withholding antiveom more likely outweigh the risk of administration in appropriate clinical setting. Acute adverse events have been reported following administrations of antivenom to mothers but only 1 case of serum sickness has been reported in pregnant mother ${ }^{11}$.

\section{Conclusion:}

Management of snakebite in pregnancy is very much challenging. Snakebite in pregnancy carries a significant risk on mother and fetus. Fetal survival depends on maternal survival. Considering the risk benefit early treatment is imperative.

Competing interest: The authors declare that they have no competing interests.

\section{References:}

1. Langley RL. Snake bite in Pregnancy. A literature Review; Widerness and Environmental Medicine. 2010:21:54-60.

2. Seneviratne SL,de Silva CE,Fonseka MMD, Pathmeswaran A,Gunatilake SB,de Silva HJ.Envenoming due to snake bite during pregnancy.Trans $R$ Soc Trop Med Hyj.2002;96:272274.

3. Dunnihoo DR,Rush BM,Wise RB,Brooks GG,Otterson WN.Snake bite Poisoning in Pregnancy.A review of the literature.J Reprod Med. 1992; 37:653-658.

4. Intrauterine fetal death caused by Pit Viper venom poisoning in early pregnancy-A Case Report.Gynecol Obstet Invest.2004;114-116.

5. Faiz MA, Hossain M, Amin R and Ghose A (2008) National guideline of Management of snake bite. $2^{\text {nd }}$ Edition, DGHS, Dhaka

6 .http://www.bnews24.com/details. php?id= $139775 \&$ cid $=2$

7. Langely R. A review of venomous animal bites and stings in pregnant patients. Wilderness Environ Med.2004;15:207 215.

8. Warrell A David. Guidelines for the clinical management of snakebites in the Southeast Asia region. New Delhi, India: World Health Organization, Regional Office for Southeast Asia; 2010 .

9. SAM.Kularatne1 Epidemiology, clinical features and management of common krait bite: a prospective study. Ceylon J Med Sci 1998;41:53-9.

10. James RF. Snakebite in pregnancy. Lancet 1995; 28(2): 731 .

11. Lurie Y,Bentur Y.Vipera palaestinae bite and serum sickness during pregnancy Emerg Med.(In press) 